\title{
Combination of anterior superior mesenteric vein-first and right posterior superior mesenteric artery-first approaches for uncinate process dissection in minimally invasive pancreaticoduodenectomy
}

\author{
Ronggui Lin, Xianchao Lin, Fengchun Lu, Yuanyuan Yang, Congfei Wang, Haizong Fang, Shi Wen, \\ Yanchang Chen, Heguang Huang \\ Department of General surgery, Fujian Medical University Union Hospital, Fuzhou, China \\ Contributions: (I) Conception and design: R Lin, H Huang; (II) Administrative support: F Lu, Y Chen; (III) Provision of study materials or patients: \\ All authors; (IV) Collection and assembly of data: X Lin, F Lu, Y Yang, C Wang; (V) Data analysis and interpretation: H Fang, S Wen; (VI) \\ Manuscript writing: All authors; (VII) Final approval of manuscript: All authors. \\ Correspondence to: Heguang Huang. Department of General surgery, Fujian Medical University Union Hospital, 29 Xinquan Road, Fuzhou, China. \\ Email: Heguanghuang2@163.com.
}

Background: Uncinate process dissection is a key step in minimally invasive pancreaticoduodenectomy (MIPD), including laparoscopic and robotic procedures, which increase the intraoperative blood loss and operative time and decrease the R0 resection rate if improperly handled. However, few studies have reported the operative skills in detail.

Methods: We performed uncinate process dissection using a combination of the anterior superior mesenteric vein (SMV)-first approach and the right posterior superior mesenteric artery (SMA)-first approach in MIPD for 138 patients with periampullary tumors between March 2017 and October 2019. The demographic and perioperative data of all the patients were collected to evaluate the efficacy of this method.

Results: All patients underwent an uneventful operation. An assistant incision was performed to separate extensive adhesion between the tumor and the SMV in 3 patients. The combined approach had a notably shorter operation time and resection time, less intraoperative blood loss and a shorter postoperative hospital stay than the traditional approach $(\mathrm{P}<0.05)$. There were no significant differences in conversion rate, numbers of harvested lymph node or postoperative complications, including postoperative pancreatic fistula, bile leakage, delayed gastric emptying, postoperative bleeding and reoperation between the two groups $(\mathrm{P}>0.05)$. There were no deaths during the perioperative period.

Conclusions: The combination of the anterior SMV-first approach and the right posterior SMA-first approach is a safe and feasible technique for uncinate process dissection in MIPD.

Keywords: Minimally invasive; pancreaticoduodenectomy (PD); uncinate process; approach

Submitted Feb 14, 2020. Accepted for publication Jul 15, 2020.

doi: $10.21037 /$ gs-20-228

View this article at: http://dx.doi.org/10.21037/gs-20-228

\section{Introduction}

Pancreaticoduodenectomy (PD) is the classic procedure for periampullary tumors $(1,2)$. With the rapid developments and innovations in laparoscopic technologies, improvements in surgical skills and summarizations of operative experience, minimally invasive pancreaticoduodenectomy (MIPD) methods, including laparoscopic pancreaticoduodenectomy (LPD) and robotic pancreaticoduodenectomy (RPD), have proven feasible and safe for peri-ampullary tumors (3) and 

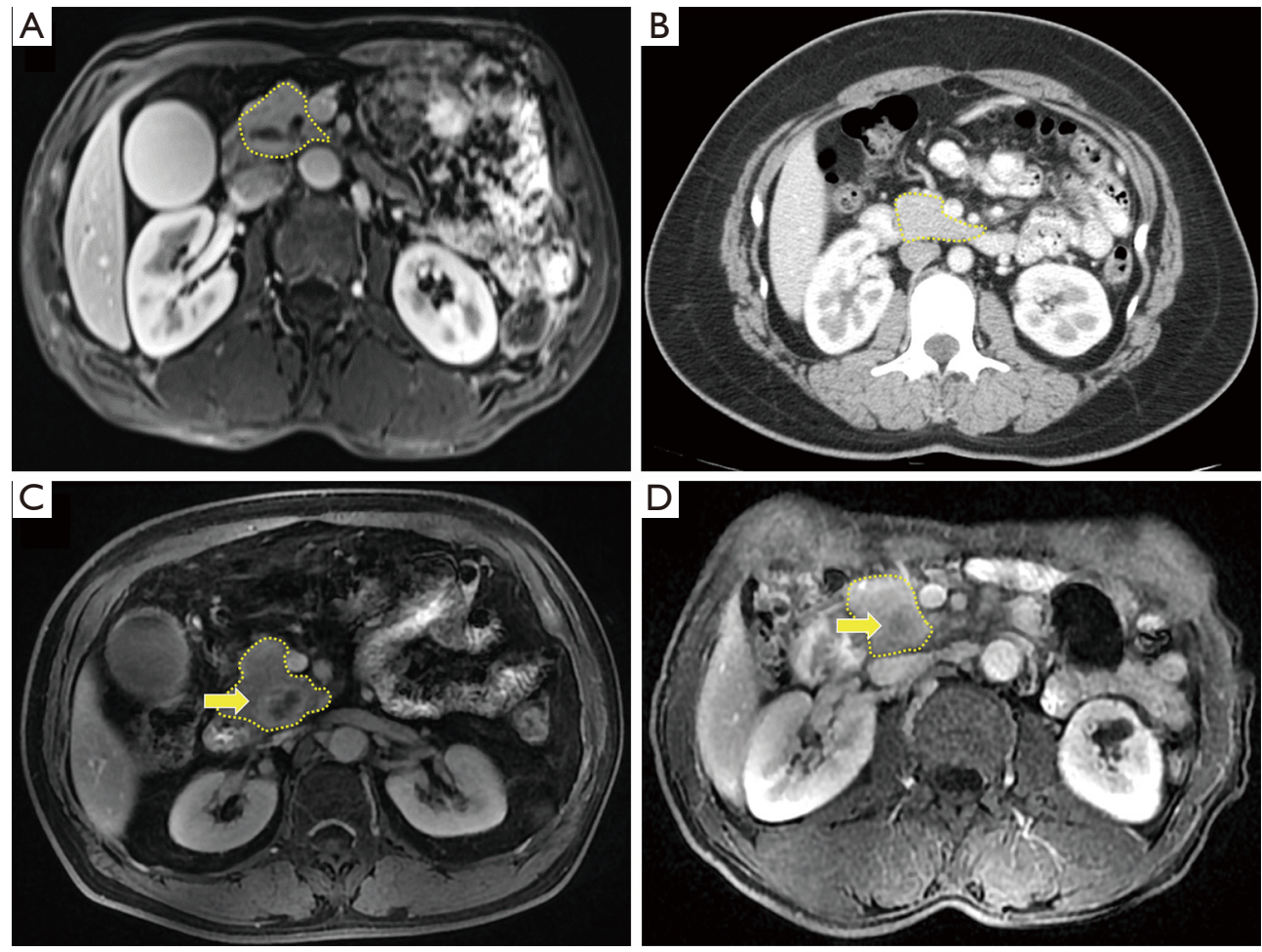

Figure 1 Imaging examination of different morphologies of the uncinate process. (A) MRI shows a short and thin uncinate process with its internal edge not reaching the left wall of the SMV. (B) CT shows a long and thick uncinate process with its internal edge exceeding the left wall of the SMA. (C) MRI indicates a tumor (arrow) located at a long and thick uncinate process. (D) MRI indicates a tumor (arrow) located at a short and thick uncinate process.

have been adapted as routine procedures in some highvolume pancreatic centers (4-7). However, MIPD is not routinely performed worldwide due to the steep learning curve $(8,9)$, the resultant serious complications and doubts about the extent of curative resection, including margin status and lymph node yield. Some critical steps of MIPD, including uncinate process dissection (10) and digestive reconstruction, especially laparoscopic pancreaticojejunostomy $(11,12)$, still confuse pancreatic surgeons.

Uncinate process dissection indicates the separation of the uncinate process from the superior mesenteric vein (SMV), superior mesenteric artery (SMA) and retroperitoneum. However, improper dissection of the uncinate process may increase intraoperative blood loss and operation time and decrease the R0 resection rate $(13,14)$ in MIPD. First, uncinate process dissection is a critical step, and it is generally the final step in removing the specimen in most traditional open pancreaticoduodenectomy (OPD) and MIPD. Uncinate process dissection can result in a palliative $\mathrm{R} 2$ resection in cases of SMA involvement after the irreversible step of dividing the pancreatic neck. Second, the difficulties of uncinate process dissection are increased in some patients, such as those with a long and thick uncinate process, chronic pancreatitis with extensive adhesion, uncinate process carcinoma or SMV involvement (15) (Figure 1). Third, the rich blood flow of the uncinate process area is supplied by the anastomotic arch, which is composed of the inferior pancreaticoduodenal artery (IPDA) arising from the SMA and the superior pancreaticoduodenal artery (SPDA) arising from the gastroduodenal artery (GDA). The arteries and the accompanying veins require careful dissection and ligation. Fourth, some important variable vessels, such as an aberrant right hepatic artery (RHA) or common hepatic artery (CHA) arising from the SMA, often course through this area and should be clearly identified to prevent injury, which can result in severe complications. However, few reports have described the operative skills required for uncinate process dissection in 
detail.

In the present study, we summarized a novel method of uncinate process dissection in MIPD by combining the anterior SMV-first and right posterior SMA-first approaches. The technique showed obvious superiority and was safe and feasible in MIPD. We present the following article in accordance with the STROBE Reporting checklist (available at http://dx.doi.org/10.21037/gs-20-228).

\section{Methods}

\section{Patients}

A total of 138 patients with periampullary tumors who underwent MIPD with uncinate process dissection via the combination of the anterior SMV-first and right posterior SMA-first approaches were enrolled in this study between March 2017 and October 2019. A single group of experienced surgeons who have performed more than 200 LPD and 50 RPD procedures since December 2014 performed the operations. The demographic data (age, sex, body mass index (BMI), American Society of Anesthesiology (ASA) classification, tumor location and type of pathology) and perioperative data (total operative time, resection time, intraoperative blood loss, postoperative hospital stay and postoperative complication) of all the patients were collected and analyzed retrospectively. The study was conducted in accordance with the Declaration of Helsinki (as revised in 2013). Approval from the institutional review board was not required for this retrospective study. Written informed consent was obtained from the patients for publication of this manuscript and any accompanying images.

\section{Operative techniques}

(I) The gastrocolic ligament was divided to expose the pancreas after exploration of the abdominal cavity to exclude distant or implantation metastasis.

(II) The separation was initiated via the anterior SMVfirst approach. The CHA and SMV were dissected separately at the superior and inferior edges of the pancreatic neck. The right gastric artery (RGA) and GDA were ligated in sequence to expose the portal vein $(\mathrm{PV})$ behind the CHA. The posterior space of the pancreatic neck was sufficiently separated upwards in front of the PV and the SMV.

(III) The separation then switched to the right posterior
SMA-first approach. The hepatic flexure of the colon was mobilized, followed by kocherization of the duodenum. The right colic vein (RCV) and the gastrocolic trunk (GCT) were divided at the root. During the right posterior separation, the inferior vena cava (IVC), the left renal vein (LRV) and the right genital vein were well protected, and the origin of the SMA was dissected superior to the LRV in front of the aorta (Figure $2 A$ ).

(IV) After the determination of resectability by identifying the PV-SMV and SMA, the distal stomach was resected, the neck of the pancreas was divided (Figure 2B), and the proximal jejunum was transected and transposed behind the superior mesenteric vessels to the right abdomen through the separated tunnel.

(V) The SMA was further longitudinally dissected, and the IPDA was ligated (Figure 2C). The first jejunal artery (FJA) was preserved when the IPDA and FJA had a common trunk. During the dissection of the SMA, the right $180^{\circ}$ periarterial connective tissue was removed to achieve an $\mathrm{R} 0$ resection, and the uncinate process was dissected ventrally.

(VI) The uncinate process became thinner after the separation via the right posterior approach, and it was dissected cranially and dorsally via the anterior approach (Figure 2D,E). The separation moved to the combined approach by retracting the duodenum and pancreatic head superolaterally with a $45-60^{\circ}$ clockwise rotation (Figure $2 F, G$ ). The combined approach provided a clear direct view and sufficient exposure when the uncinate process was gradually separated from the SMV, the SMA and the retroperitoneum. The superior pancreaticoduodenal vein (SPDV) was ligated to achieve uncinate process dissection (Video 1).

(VII) The gallbladder was resected, the common bile duct was transected, and the specimen was removed with en bloc resection (Figure $2 \mathrm{H}$ ).

(VIII) Digestive construction was performed according to the following sequence: pancreaticojejunostomy with the duct-to-mucosa anastomosis method, choledochojejunostomy and gastrointestinal anastomosis.

\section{Statistical analysis}

The data are expressed as the mean \pm SD for continuous 

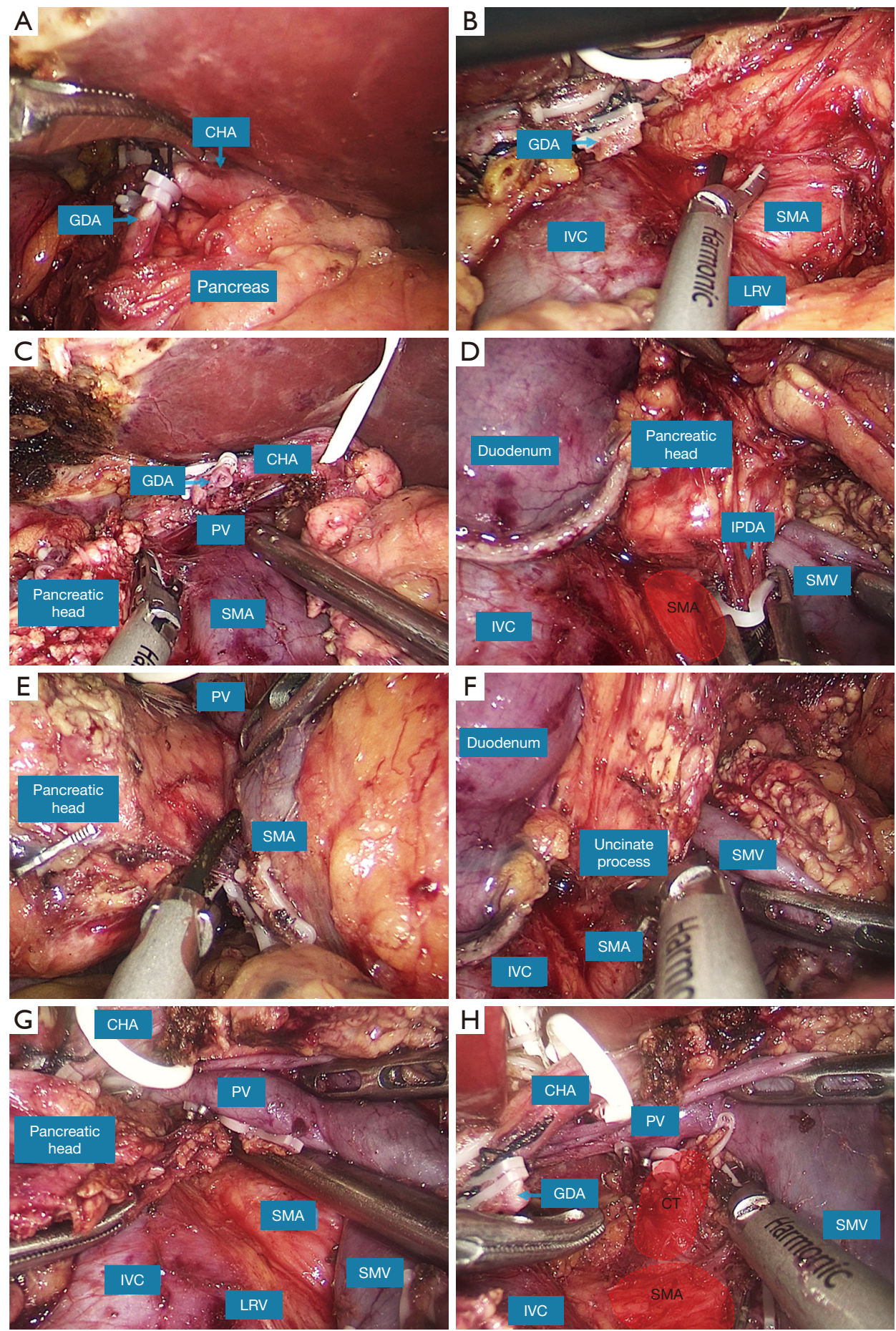

Figure 2 Operative skills of uncinate process dissection via the combined approach in MIPD. (A) Dissection of the CHA and ligation of the GDA using the anterior SMV-first approach. (B) Dissection at the origin of the SMA using the right-posterior SMA-first approach. (C) Division of pancreatic neck after the determination of tumor resectability. (D) Ligation of the IPDA during the right-posterior SMA-first approach. (E) Dissection of the uncinate process from the SMV cranially and dorsally using the anterior SMA-first approach. (F,G) Separation of the uncinate process using the combined approach, which simultaneously provided a clear and direct view of the SMA and the SMV. (H) An overall view of important vessels after removal of the specimen. PV, portal vein; SMV, superior mesenteric vein; SMA, superior mesenteric artery; CHA, common hepatic artery; GDA, gastroduodenal artery; IVC, inferior vena cava; LRV, left renal vein; CT, celiac trunk. 
Table 1 The demographic characteristics

\begin{tabular}{|c|c|}
\hline Demographic data & $\mathrm{n}$ \\
\hline Patients & 138 \\
\hline Age (years) & $52.8 \pm 10.2$ \\
\hline \multicolumn{2}{|l|}{ Gender } \\
\hline Male & 63 \\
\hline Female & 75 \\
\hline BMI $\left(\mathrm{kg} / \mathrm{m}^{2}\right)$ & $23.3 \pm 1.8$ \\
\hline \multicolumn{2}{|l|}{ ASA } \\
\hline I & 91 \\
\hline II & 39 \\
\hline III & 8 \\
\hline \multicolumn{2}{|l|}{ Tumor location } \\
\hline Pancreatic head & 62 \\
\hline Ampullary & 28 \\
\hline Duodenum & 32 \\
\hline Distal common bile duct & 16 \\
\hline \multicolumn{2}{|l|}{ Type of pathology } \\
\hline Benign & 72 \\
\hline Malignant & 66 \\
\hline Tumor size (cm) & $2.6 \pm 1.0$ \\
\hline
\end{tabular}

BMI, body mass index; ASA, American Society of Anesthesiology.

variables and as proportions and frequencies for categorical variables. Perioperative factors and postoperative complications were compared between the two groups with the Chi-square test, Fisher's exact test and Student $t$-test. A P value $<0.05$ was considered statistically significant. Data were analyzed using SPSS version 20.0 (SPSS, Inc., Chicago, IL, USA).

\section{Results}

The demographic data of the patients are shown in Table 1. A total of 138 patients were enrolled in this study, including 63 males and 75 females with a mean age of $52.8 \pm 10.2$ years. The mean BMI was $23.3 \pm 1.8 \mathrm{~kg} / \mathrm{m}^{2}$. The tumor was located at the pancreatic head in 62 patients, the ampulla in 28 patients, the duodenum in 32 patients and the distal common bile duct in 16 patients. There were 72 patients with benign tumors and 66 patients with malignant tumors, with a mean tumor size of $2.6 \pm 1.0 \mathrm{~cm}$. The perioperative data of the patients are shown in Table 2 . Ninety-six patients underwent LPD, and 42 patients underwent RPD. All patients underwent an uneventful operation. An assistant incision was performed to separate extensive adhesion between the tumor and the SMV in 3 patients. There were no deaths during the perioperative period.

To evaluate the efficacy of the combined approach for MIPD, we introduced our first 65 MIPD cases using the anterior SMV-first approach for comparison. The results showed that the combined approach had a notably shorter operation time $(345.4 \pm 51.9$ vs. $410.8 \pm 73.11 \mathrm{~min})$ and resection time $(122.7 \pm 20.9$ vs. $178.2 \pm 43.2 \mathrm{~min})$, less intraoperative blood loss $(153.2 \pm 54.5$ vs. $242.7 \pm$ $186.4 \mathrm{~mL}$ ) and a shorter postoperative hospital stay $(13.5 \pm 5.1$ vs. $15.2 \pm 6.0$ days $)$ than the traditional approach $(\mathrm{P}<0.05)$. The main reason may lie in the superiority of combined approach. However, most of the operations using the traditional approach were performed during the learning curve, as reported 40 cases in several studies $(3,9)$. There were no significant differences in the conversion rate

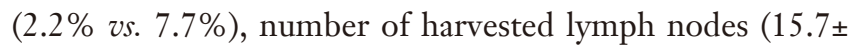
3.2 vs. $14.95 \pm 2.5$ ) or postoperative complications, including postoperative pancreatic fistula (16) (grade B + C, $12.3 \%$ vs. $13.8 \%$ ), bile leakage (1.4\% vs. $4.6 \%$ ), delayed gastric emptying (3.8\% vs. $3.1 \%)$, postoperative bleeding (3.6\% vs. $3.1 \%)$ and reoperation (1.9\% vs. $3.1 \%)$ between the two groups $(\mathrm{P}>0.05)$.

\section{Discussion}

MIPD has not been widely performed since it is associated with increased risks of morbidity and mortality. Three published randomized controlled trials (RCTs) have compared the perioperative outcomes of LPD to OPD (17). The PLOT trial showed that LPD had postoperative complications and mortality rates comparable to those of OPD but had a shorter postoperative hospital stay (18). The PAUDALP trial showed that LPD had a lower morbidity rate and CCI score than OPD and a remarkably shorter postoperative hospital stay (19). However, the LEOPARD-2 trial was prematurely stopped due to concerns about a higher 90-day mortality in the LPD group (20). However, these three RCTs had some limitations, including a small sample size (PLOT, 32 cases; PAUDALP, 32 cases; and LEOPARD-2, 50 cases) and selection bias resulting from the learning curve. A recent multicenter RCT (21) 
Table 2 The surgical outcomes and postoperative factors between the combined and traditional approaches for MIPD

\begin{tabular}{|c|c|c|c|}
\hline Variables & Combined approach, $n=138$ & Traditional approach, $\mathrm{n}=65$ & $P$ value \\
\hline Resection time (min) & $122.7 \pm 20.9$ & $178.2 \pm 43.2$ & $<0.0001$ \\
\hline Intraoperative blood loss (mL) & $153.2 \pm 54.5$ & $242.7 \pm 186.4$ & $<0.0001$ \\
\hline Conversions, $\mathrm{n}(\%)$ & $3(2.2 \%)$ & $5(7.7 \%)$ & 0.1137 \\
\hline Postoperative hospital stay (days) & $13.5 \pm 5.1$ & $15.2 \pm 6.0$ & 0.0373 \\
\hline \multicolumn{4}{|l|}{ Postoperative complications, n (\%) } \\
\hline Pancreatic fistula & $17(12.3 \%)$ & $8(13.8 \%)$ & 0.7385 \\
\hline Grade B & $15(10.9 \%)$ & $7(10.8 \%)$ & \\
\hline Delayed gastric emptying & $6(3.8 \%)$ & $2(3.1 \%)$ & 1.0000 \\
\hline Postoperative bleeding & $5(3.6 \%)$ & $2(3.1 \%)$ & 1.0000 \\
\hline Reoperation & $3(1.9 \%)$ & $2(3.1 \%)$ & 0.6561 \\
\hline
\end{tabular}

MIPD, minimally invasive pancreaticoduodenectomy.

(TJDBPS01, NCT03138213) comparing the perioperative outcomes of LPD vs. OPD was conducted in China from May 2018 to December 2019. The study included 14 highvolume pancreatic centers that had performed more than 100 LPDs (including our center). The results showed that LPD had postoperative complication and mortality rates comparable to those of OPD as well as a shorter postoperative hospital stay (not published). Therefore, MIPD is recommended to be performed in specialized high-volume centers with experienced groups.

Dissection of the uncinate process is a critical step in MIPD that increases intraoperative blood loss and operative time and decreases the $\mathrm{R} 0$ resection rate if improperly handled. The development of a method for the perfect dissection of the uncinate process in MIPD is of great importance and should receive more attention from most pancreatic surgeons. The current commonly used approaches for uncinate process dissection mainly include the SMV-first approach and the SMA-first approach, and both approaches have their own advantages and disadvantages.

The SMV-first approach refers to first identifying the SMV, dissecting the CHA and its main branches and separating the uncinate process from the SMA, SMV and retroperitoneum using a caudal-to-cranial and ventral-to- dorsal technique. Consequently, we define the technique as an anterior SMV-first approach to provide a more precise description. Many pancreatic surgeons use this approach in most OPD and MIPD procedures. In this approach, the neck of the pancreas is divided, followed by the separation of the uncinate process cranially and dorsally from the superior mesenteric vessels and retroperitoneum. The superior and inferior edges of the pancreas are dissected early to expose important vessels, including the CHA, GDA and PV-SMV, and to identify vascular variations, such as a variable CHA. This approach also allows the early identification of PVSMV involvement during the separation of the posterior space of the pancreatic neck. However, the anterior SMVfirst approach overemphasizes the early dissection of the PV-SMV and neglects the importance of early identification of the SMA. Although tumor resectability is mainly determined with preoperative imaging examinations, including computed tomography (CT) and magnetic resonance imaging (MRI), it is difficult to distinguish adhesions or peripancreatic inflammatory "stranding" from local tumor invasion in some patients, especially those who have received neoadjuvant chemotherapy or neoadjuvant chemoradiotherapy, using preoperative imaging $(22,23)$. Palliative resection is generally passively performed with an $\mathrm{R} 2$ resection after the division of the pancreatic neck 
without early determination of SMA involvement. In addition, the ligation of draining veins without blocking the blood supply to the pancreatic head is a priority in aggravated regional congestion and increased intraoperative blood loss during uncinate process dissection. For patients with a long and thick uncinate process and those with uncinate process carcinoma or PV-SMV involvement, it is difficult to separate the uncinate process from the superior mesenteric vessels and to remove the connective tissues to the right $180^{\circ}$ of the SMA to achieve an R0 resection.

The SMA-first approach was first described by Pessaux in 2006 (24) and emphasizes the early identification of the SMA for the assessment of tumor resectability before performing the irreversible step of pancreatic neck division. This approach provides better exposure of the SMA for the clearance of the right $180^{\circ}$ of periarterial connective tissues with an increased $\mathrm{R} 0$ resection rate (25), early ligation of the IPDA, and early identification of vascular variations, such as a variable CHA or an RHA arising from the SMA (26). This approach is associated with a remarkable decrease in intraoperative blood loss and operation time but shows no differences in perioperative morbidity and mortality compared with standard PD (27). Other studies showed a decreased local recurrence rate and an increased survival rate (24) or a significant decrease in perioperative morbidity and hospital stay (28) using an SMA-first approach compared to standard PD. According to the existing documents, the SMA-first approaches mainly include six different approaches: the right posterior approach, medial approach, anterior approach, superior approach, left posterior approach and mesenteric approach (14,29-32). The right posterior approach is easy to master and is favored by many pancreatic surgeons (33). The right posterior approach is especially suitable for MIPD because of the coincidence of the operative approach and the laparoscopic view. It is easy to separate the retroperitoneum, locate the origin of the SMA superior to the LRV in front of the aorta and clear the right $180^{\circ}$ of the periarterial connective tissue after mobilization of the hepatic flexure of the colon and kocherization of the duodenum. Compared to the right posterior approach, the left posterior approach extensively dissects the SMA via the wide separation of the retroperitoneum through Treiz's ligament and clears $360^{\circ}$ of periarterial connective tissue (34), which may result in intractable diarrhea, and it is not recommended in the NCCN clinical practice guidelines (35). The superior approach, with its unique caudal-to-cranial view, is unsuitable for MIPD, and it is difficult to expose a low origin of the SMA. The early division of the stomach and pancreatic neck is generally performed for better exposure of the SMA in the anterior approach $(36,37)$. It is difficult to expose a high origin of the SMA in the mesenteric approach (32), and the medial uncinate approach identifies the replaced RHA late in the procedure (38). However, with the right posterior approach, it is difficult to dissect the uncinate process before the division of the pancreatic neck in patients with severe peripancreatic adhesion, uncinate process carcinoma or PV-SMV involvement, and this approach is also associated with delayed detection of the CHA and PV-SMV.

Given the advantages and disadvantages of the anterior SMV-first and right posterior SMA-first approaches, we created a novel method for uncinate process dissection in MIPD by combining the two approaches. Our experience shows that the combined approach retains the advantages of the two approaches while eliminating some of their disadvantages. The following superiorities of our approach were determined. First, blockade of the blood supply to the pancreatic head is a priority. The arch of the pancreaticoduodenal artery is the main blood supply for the head of the pancreas, and it is composed of the SPDA from the GDA and the IPDA from the SMA. The former is divided during the separation using the anterior SMV-first approach, and the latter is divided during the separation using the right posterior SMA-first approach. Additionally, the important vessel branches in the uncinate process area are visualized clearly and easily identified and ligated. Second, early and sufficient determination of tumor resectability is an advantage. The PV-SMV is detected using the anterior SMV-first approach, and the origin of the SMA is detected using the right posterior SMA-first approach. In cases of PV-SMV involvement, it is easy to perform vein resection or reconstruction because the only adhesion is between the tumor and vein after division of the pancreatic neck and dissection of the uncinate process. Third, the clear identification of vascular variations is an advantage. Although thin-slice CT is helpful for identifying vascular variations preoperatively, clear intraoperative identification is more important for protecting variable vessels. Aberrant hepatic artery is a common vascular variation in MIPD, and it has a morbidity of approximately $25 \%$ (39) such as a replaced RHA arising from the SMA. Using the combined approach, the CHA and SMA are dissected early and sufficiently, which significantly decreases the incidence of important vessel injury. Fourth, the "no-touch" isolation technique is an advantage. The peripancreatic vessels are 
ligated first, and pression or touch of the tumor is avoided using the combined approach during surgery, which adheres to the "no-touch" principle for tumors. Fifth, sufficient exposure of the uncinate process is achieved. The combined approach provides clear visualization of the uncinate process and reduces the difficulty of uncinate process dissection. The SMA is clearly identified, and it is easy to clear the right $180^{\circ}$ of the connective tissue of the SMA, which increases the $\mathrm{R} 0$ resection rate and decreases the risks of local recurrence.

There are some limitations of the present study. This study was a retrospective study instead of a prospective RCT study, and it might be affected by bias. A single experienced group performed the surgeries, but our department is a high-volume center that has performed MIPD in more than 200 cases. A multiple-center prospective RCT may be needed in the future to further verify the efficacy of this novel technique.

\section{Conclusions}

The anterior SMV-first approach combined with the right posterior SMA-first approach is a safe and feasible technique with obvious benefits for uncinate process dissection in MIPD.

\section{Acknowledgments}

Funding: The study was supported by Medical Minimally Invasive Center Program of Fujian Province, China (No. 2017-171), Joint Funds of Scientific and Technological Innovation Program of Fujian Province (No. 2017Y9059), Key Clinical Specialty Discipline Construction Program of Fujian Province, China (No. 2012-649).

\section{Footnote}

Reporting Checklist: The authors have completed the STROBE reporting checklist. Available at http://dx.doi. org/10.21037/gs-20-228

Data Sharing Statement: Available at http://dx.doi. org/10.21037/gs-20-228

Conflicts of Interest: All authors have completed the ICMJE uniform disclosure form (available at http://dx.doi. org/10.21037/gs-20-228). The authors have no conflicts of interest to declare.
Ethical Statement: The authors are accountable for all aspects of the work in ensuring that questions related to the accuracy or integrity of any part of the work are appropriately investigated and resolved. The study was conducted in accordance with the Declaration of Helsinki (as revised in 2013). Written informed consent was obtained from the patients for publication of this manuscript and any accompanying images. Approval from the institutional review board was not required for this retrospective study.

Open Access Statement: This is an Open Access article distributed in accordance with the Creative Commons Attribution-NonCommercial-NoDerivs 4.0 International License (CC BY-NC-ND 4.0), which permits the noncommercial replication and distribution of the article with the strict proviso that no changes or edits are made and the original work is properly cited (including links to both the formal publication through the relevant DOI and the license). See: https://creativecommons.org/licenses/by-nc-nd/4.0/.

\section{References}

1. El Nakeeb A, Askar W, Atef E, et al. Trends and outcomes of pancreaticoduodenectomy for periampullary tumors: A 25-year single-center study of 1000 consecutive cases. World J Gastroenterol 2017;23:7025-36.

2. Cameron JL, He J. Two thousand consecutive pancreaticoduodenectomies. J Am Coll Surg 2015;220:530-6.

3. Song KB, Kim SC, Lee W, et al. Laparoscopic pancreaticoduodenectomy for periampullary tumors: lessons learned from 500 consecutive patients in a single center. Surg Endosc 2020;34:1343-52.

4. Croome KP, Farnell MB, Que FG, et al. Total laparoscopic pancreaticoduodenectomy for pancreatic ductal adenocarcinoma: oncologic advantages over open approaches? Ann Surg 2014;260:633-8; discussion 638-40.

5. Torphy RJ, Friedman C, Halpern A, et al. Comparing Short-term and Oncologic Outcomes of Minimally Invasive Versus Open Pancreaticoduodenectomy Across Low and High Volume Centers. Ann Surg 2019;270:1147-55.

6. Giulianotti PC, Mangano A, Bustos RE, et al. Operative technique in robotic pancreaticoduodenectomy (RPD) at University of Illinois at Chicago (UIC): 17 steps standardized technique: Lessons learned since the first worldwide RPD performed in the year 2001. Surg Endosc 2018;32:4329-36. 
7. Wang M, Peng B, Liu J, et al. Practice Patterns and Perioperative Outcomes of Laparoscopic Pancreaticoduodenectomy in China: A Retrospective Multicenter Analysis of 1029 Patients. Ann Surg 2019. [Epub ahead of print].

8. Nagakawa Y, Nakamura Y, Honda G, et al. Learning curve and surgical factors influencing the surgical outcomes during the initial experience with laparoscopic pancreaticoduodenectomy. J Hepatobiliary Pancreat Sci 2018;25:498-507.

9. Zhang T, Zhao ZM, Gao YX, et al. The learning curve for a surgeon in robot-assisted laparoscopic pancreaticoduodenectomy: a retrospective study in a highvolume pancreatic center. Surg Endosc 2019;33:2927-33.

10. O'Sullivan AW, Heaton N, Rela M. Cancer of the uncinate process of the pancreas: surgical anatomy and clinicopathological features. Hepatobiliary Pancreat Dis Int 2009;8:569-74.

11. Du Y, Wang J, Li Y, et al. Clinical application of a modified pancreatojejunostomy technique for laparoscopic pancreaticoduodenectomy. HPB (Oxford) 2019;21:1336-43.

12. Cai Y, Luo H, Li Y, et al. A novel technique of pancreaticojejunostomy for laparoscopic pancreaticoduodenectomy. Surg Endosc 2019;33:1572-7.

13. Chen XM, Sun DL, Zhang Y. Laparoscopic versus open pancreaticoduodenectomy combined with uncinated process approach: A comparative study evaluating perioperative outcomes (Retrospective cohort study). Int J Surg 2018;51:170-3.

14. Hackert T, Werner J, Weitz J, et al. Uncinate process first--a novel approach for pancreatic head resection. Langenbecks Arch Surg 2010;395:1161-4.

15. Kang CM, Choi JY, Seong JS, et al. Pancreatoduodenectomy following neoadjuvant chemoradiation therapy in uncinate process pancreatic cancer. Pancreas 2012;41:467-73.

16. Bassi C, Marchegiani G, Dervenis C, et al. The 2016 update of the International Study Group (ISGPS) definition and grading of postoperative pancreatic fistula: 11 Years After. Surgery 2017;161:584-91.

17. Nickel F, Haney CM, Kowalewski KF, et al. Laparoscopic Versus Open Pancreaticoduodenectomy: A Systematic Review and Meta-analysis of Randomized Controlled Trials. Ann Surg 2020;271:54-66.

18. Palanivelu C, Senthilnathan P, Sabnis SC, et al. Randomized clinical trial of laparoscopic versus open pancreatoduodenectomy for periampullary tumours. Br J
Surg 2017;104:1443-50.

19. Poves I, Burdio F, Morato O, et al. Comparison of Perioperative Outcomes Between Laparoscopic and Open Approach for Pancreatoduodenectomy: The PADULAP Randomized Controlled Trial. Ann Surg 2018;268:731-9.

20. van Hilst J, de Rooij T, Bosscha K, et al. Laparoscopic versus open pancreatoduodenectomy for pancreatic or periampullary tumours (LEOPARD-2): a multicentre, patient-blinded, randomised controlled phase $2 / 3$ trial. Lancet Gastroenterol Hepatol 2019;4:199-207.

21. Zhang H, Feng Y, Zhao J, et al. Total laparoscopic pancreaticoduodenectomy versus open pancreaticoduodenectomy (TJDBPS01): study protocol for a multicentre, randomised controlled clinical trial. BMJ Open 2020;10:e033490.

22. Valls C, Andia E, Sanchez A, et al. Dual-phase helical CT of pancreatic adenocarcinoma: assessment of resectability before surgery. AJR Am J Roentgenol 2002;178:821-6.

23. Ferrone CR, Marchegiani G, Hong TS, et al. Radiological and surgical implications of neoadjuvant treatment with FOLFIRINOX for locally advanced and borderline resectable pancreatic cancer. Ann Surg 2015;261:12-7.

24. Pessaux P, Varma D, Arnaud JP. Pancreaticoduodenectomy: superior mesenteric artery first approach. J Gastrointest Surg 2006;10:607-11.

25. Pessaux P, Rosso E, Panaro F, et al. Preliminary experience with the hanging maneuver for pancreaticoduodenectomy. Eur J Surg Oncol 2009;35:1006-10.

26. Shukla PJ, Barreto SG, Kulkarni A, et al. Vascular anomalies encountered during pancreatoduodenectomy: do they influence outcomes? Ann Surg Oncol 2010;17:186-93.

27. Dumitrascu T, David L, Popescu I. Posterior versus standard approach in pancreatoduodenectomy: a casematch study. Langenbecks Arch Surg 2010;395:677-84.

28. Figueras J, Codina-Barreras A, Lopez-Ben S, et al. Cephalic duodenopancreatectomy in periampullary tumours. Dissection of the superior mesenteric artery as aninitial approach. Description of the technique and an assessment of our initial experience. Cir Esp 2008;83:186-93.

29. Rose JB, Rocha F, Alseidi A, et al. Posterior 'superior mesenteric artery first' approach for resection of locally advanced pancreatic cancer. Ann Surg Oncol 2014;21:1927-8.

30. Inoue Y, Saiura A, Yoshioka R, et al. Pancreatoduodenectomy With Systematic Mesopancreas Dissection Using a Supracolic Anterior Artery-first 
Approach. Ann Surg 2015;262:1092-101.

31. Nagakawa Y, Hosokawa Y, Sahara Y, et al. A Novel "Artery First" Approach Allowing Safe Resection in Laparoscopic Pancreaticoduodenectomy: The Uncinate Process First Approach. Hepatogastroenterology 2015;62:1037-40.

32. Zhu J, Han D, Li X, et al. Inferior Infracolic 'Superior Mesenteric Artery First' Approach with a No-Touch Isolation Surgical Technique in Patients with a Borderline Resectable Cancer of the Pancreatic Head. Ann Surg Oncol 2016;23:976-80.

33. Vallance AE, Young AL, Pandanaboyana S, et al. Posterior Superior Mesenteric Artery First Dissection Versus Classical Approach in Pancreaticoduodenectomy: Outcomes of a Case-Matched Study. Pancreas 2017;46:276-81.

34. Cho A, Yamamoto H, Kainuma O. Tips of laparoscopic pancreaticoduodenectomy: superior mesenteric artery first approach (with video). J Hepatobiliary Pancreat Sci

Cite this article as: Lin R, Lin X, Lu F, Yang Y, Wang C, Fang H, Wen S, Chen Y, Huang H. Combination of anterior superior mesenteric vein-first and right posterior superior mesenteric artery-first approaches for uncinate process dissection in minimally invasive pancreaticoduodenectomy. Gland Surg 2020;9(5):1396-1405. doi: 10.21037/gs-20-228
2014;21:E19-21.

35. Tempero MA, Malafa MP, Al-Hawary M, et al. Pancreatic Adenocarcinoma, Version 2.2017, NCCN Clinical Practice Guidelines in Oncology. J Natl Compr Canc Netw 2017;15:1028-61.

36. Hirota M, Kanemitsu K, Takamori H, et al. Pancreatoduodenectomy using a no-touch isolation technique. Am J Surg 2010;199:e65-8.

37. Cai Y, Gao P, Li Y, et al. Laparoscopic pancreaticoduodenectomy with major venous resection and reconstruction: anterior superior mesenteric artery first approach. Surg Endosc 2018;32:4209-15.

38. Hackert T, Buchler MW. An Innovative Technique for Pancreatic Head Resection: The "Uncinate First" Approach. Surg Technol Int 2011;21:92-6.

39. Hiatt JR, Gabbay J, Busuttil RW. Surgical anatomy of the hepatic arteries in 1000 cases. Ann Surg 1994;220:50-2. 